DOI: $10.20396 /$ cel.v61io.8653021

(c) $(1)(9)$

\title{
UMA PROPOSTA DE DESCRIÇÃO DO SISTEMA DE MENSAGEM NA ORGANIZAÇÃO FUNCIONAL DISCURSO
}

\author{
GIACOMO FIGUEREDO ${ }^{1}$
}

\begin{abstract}
RESUMO: Este artigo investiga as funções linguísticas responsáveis pela organização textual do discurso. Mais especificamente, descreve o sistema semântico-discursivo de MENSAGEM, o qual responde pelo gerenciamento da produção e acúmulo de significado no texto. Para tanto, explora a estrutura do discurso tendo como ponto de partida a relação entre esse e a gramática oracional que o realiza. Em seguida, descreve cada opção do sistema, bem como a forma como opera ao longo do fluxo textual, e assim assumindo valor nas relações que estabelece frente a outras opções. Para promover a descrição, utilizou-se o português brasileiro como língua de investigação. Um corpus com 100 mil tokens foi compilado com base na tipologia da língua no contexto de cultura. Os textos foram analisados segundo a manifestação estrutural, relações funcionais entre opções sistêmicas, e o significado gerado pela organização discursiva das mensagens. Ao final, o artigo mostra como as diferentes opções de MENSAGEM pré-selecionam funções na gramática, fazendo com que cada mensagem seja contextualizada, incorporando-se ao texto de forma a dar algum direcionamento à fase a qual pertence. $\mathrm{O}$ artigo mostra ainda o potencial sistêmico pelo qual diferentes tipos de texto determinam opções distintas na gramática e semântica textuais.

Palavras-chave: estrutura do discurso; fluxo discursivo; metafunção textual; sistema de MENSAGEM.
\end{abstract}

ABSTRACT: This paper aims at describing the systemic organization of the discourse textual component. It focuses on the discourse semantic system of MESSAGE - the system pre-selected by periodicity that is responsible for accumulating meaning in text. In order to do so, the paper takes Brazilian Portuguese as language under investigation. It explores Brazilian Portuguese's discourse structure departing from its relation to clause grammar as well as patterns of discourse composing text. A corpus of a 100,000 tokens was compiled according to the typology of language in the context of culture. After identifying grammatical functions pre-selected by MESSAGE, the paper describes different message structural patterns and offers the motivation for features as well as their agnating patterns and levels of delicacy. Results show how different choices in the system shape information flow and explains the relationship between text type and different configurations of textual grammar and discourse semantics.

Keywords: discourse structure; information flow; textual metafunction; system of MESSAGE.

\section{INTRODUÇÃO}

A análise da estrutura do discurso, quando considerada sua funcionalidade, demonstra que o texto ${ }^{2}$ não é simplesmente um conjunto de orações (HALLIDAY;

${ }^{1}$ Universidade Federal de Ouro Preto (UFOP), Ouro Preto, MG, Brasil. giacomojakob@gmail.com https://orcid.org/0000-0002-0967-244X

${ }^{2} \mathrm{O}$ modelo de sistema linguístico adotado neste artigo possui três estratos: fonologia, gramática e semântica discursiva. Este último, portanto, não distingue a semântica do discurso e, desta forma, o texto é considerado como uma unidade integrada de semântica e discurso. 
HASAN, 1976; MATHESIUS [1939] 1983; NEIS, 1981). Diversos trabalhos (GREGORY, 1985; KOCH; MARCUSCHI, 1998) esclarecem o modo pelo qual a organização do texto necessita de funções que extrapolam aquelas da gramática da oração - às quais se denominam funções do discurso, localizadas no estrato da semântica discursiva (GLEASON, 1968; KOCH, 2006).

A identificação dessas funções permite a descrição da estrutura do discurso de forma diferente daquela da gramática (HASAN, 1979). Porém, se por um lado a dissociação entre discurso e gramática é reveladora da estrutura própria do discurso, ela pode levar, por outro lado, a um problema de caráter descritivo - uma vez que o discurso é realizado pela gramática (HAIMAN; THOMPSON, 1988; LEMKE, 1984). Este é o caso do papel do tema descrito por Ilari (1992) no português, no qual um elemento da oração tem função no discurso. Assim como também é o caso de relações coesivas (FÁVERO, 1991; HALLIDAY; HASAN, 1976), da gramática do texto (HALLIDAY, 1992; VILELA; KOCH, 2001) e da sequenciação textual (KOCH; ELIAS, 2006).

Apesar de várias correlações entre fluxo discursivo e escolhas gramaticais terem sido estabelecidas em estudos anteriores (van DIJK, 1977; HASAN, 1979; MARCUSCHI, 1983), o problema da dissociação faz com que a pesquisa se limite, em grande medida, a relacionar estrutura do discurso e estrutura da oração - como é o caso dos estudos sobre tematização (FIRBAS, 1964; KOCH, 2006; MARTIN, 1992). Esse fato não permite que alguns aspectos importantes dessa relação sejam descritos mais detalhadamente, tais como a organização sistêmica que gera os padrões estruturais.

Em particular, cabe ainda estabelecer com precisão as unidades do discurso que se relacionam diretamente com a gramática; os sistemas que são gerados por essa unidade; as funções gramaticais selecionadas para realizar os sistemas dessa unidade e, por fim, a estrutura do discurso que é gerada nesse processo.

Para esse fim, a primeira medida é tratar o componente semântico e o componente discursivo da língua como um único estrato - a semântica-discursiva (GREGORY, 1985; MARTIN, 2008; ROSE, 2006). Esta medida se justifica para a abordagem adotada na presente descrição pelo fato de a semântica - o componente que responde pelo sentido - se organiza no discurso. Assim, um elemento linguístico isolado do discurso perde o sentido uma vez que perde sua contextualização.

Uma possibilidade de abordar este problema é promover uma descrição dos sistemas semântico-discursivos que geram o fluxo. A partir dessa descrição, a unidade discursiva pode ser identificada, o que, por sua vez, facilita a explicação de diferentes padrões de fluxo discursivo e as escolhas gramaticais que os realizam.

Diante dessa questão, o presente artigo tem como objetivo principal apresentar uma descrição do sistema semântico que gera a estrutura do fluxo discursivo. À unidade básica do discurso que aqui será identificada, dar-se-á o nome de 〈mensagem〉. Da mesma forma, o sistema será denominado «sistema de 
MENSAGEM' ${ }^{3}$. O artigo promove ainda a descrição tendo o português brasileiro (PB) como língua de investigação.

Mais especificamente, o presente artigo visa (i) descrever a natureza da unidade básica do texto - a mensagem - que interage com a gramática, (ii) os sistemas (opções paradigmáticas) que organizam a relação entre discurso e gramática - o sistema de MENSAGEM, e (iii) os tipos de realização gramatical que o fluxo necessita no PB.

Para alcançar o objetivo, o artigo tem como ponto de partida o aspecto semântico da oração (FIRBAS, 1964; HALLIDAY; HASAN, 1976; MATHESIUS, 1983). Em seguida, busca correlacionar as opções do sistema de MENSAGEM, por um lado, com o TEMA - componente textual da gramática que a MENSAGEM préseleciona - e, por outro, com o fluxo discursivo gerado por esse sistema. Para tanto, pauta-se pela perspectiva sistêmico-funcional e confere ao eixo paradigmático (SAUSSURE, [1916] 2006) papel principal na organização da língua (MARTIN, 2013).

Para descrever a MENSAGEM, um corpus em português brasileiro foi utilizado como fonte de dados, extraído do CALIBRA (Catálogo da Língua Brasileira). O CALIBRA é um corpus monolíngue do português brasileiro compilado com base na tipologia da língua no contexto de cultura (HALLIDAY; MATTHIESSEN, 2014). Uma vez que se investigam aspectos funcionais da língua no texto portanto, aspectos da língua utilizada pelos falantes em contextos sociais - são adotados como metodologia de análise e descrição a Teoria Geral de Descrição (GLEASON, 1965; HALLIDAY, 1961). Os textos foram analisados segundo a manifestação estrutural, as relações funcionais entre as opções sistêmicas, e o significado gerado pela organização das mensagens.

\section{O TEXTO COMO UNIDADE DE SIGNIFICADO}

O que permite ao texto configurar-se como uma unidade de significado oposto a uma coleção de orações - é a sua organização textual (FIRBAS, 1964), que se dá pelo acúmulo de informação no sistema linguístico. Este acúmulo leva, subsequentemente, à produção de significado através da organização de funções linguísticas (DANEŠ, 1994), tanto no nível da gramática, com o sistema de TEMA, quanto da semântica discursiva, com a MENSAGEM (tessitura estrutural) (HALLIDAY; HASAN, 1976). Nesse aspecto, a gramática realiza o sentido semântico que se apresenta no discurso - daí a formulação do estrato da semânticadiscursiva (ZAPPAVIGNIA; MARTIN, 2018). Portanto, cabe à gramática não apenas estruturar sentidos isolados, mas, de outra forma, sentidos contextualizados conforme a função dos textos os quais compõem.

Do ponto de vista da produção de significado, a mensagem se configura como a informação simples que contribui para a produção do texto. Do ponto de vista do

${ }^{3}$ Adotando-se a notação sistêmica, os nomes de sistemas são grafados em versalete (ex.: TEMA), funções gramaticais com inicial maiúscula (ex.: Tema), funções semânticas e classes com minúsculas (ex.: tema), opções sistêmicas entre colchetes (ex.: [tema]). 
acúmulo, ela contribui para a produção quando justaposta a outras mensagens. O sistema de MENSAGEM, por sua vez, oferece os recursos semânticos que organizam cada mensagem conforme a tessitura.

A tessitura é a propriedade que os sistemas semióticos possuem de estabelecer quais são as relações possíveis entre funções estruturais no processo de acúmulo de informação (HALLIDAY; HASAN, 1976). Por esse motivo, 'texto' é uma unidade do estrato semântico-discursivo (cf. KOCH; MARCUSCHI, 1998), composto por mensagens - isto é, unidades semânticas (MARTIN, 1992). As mensagens, por sua vez, é que são realizadas por orações - isto é, unidades gramaticais (MARTIN; ROSE, 2007). Por meio da tessitura, cada mensagem acrescenta um quantum de informação ao significado global do texto (KOCH, 2006; MARTIN; ROSE, 2007).

A tessitura pode portanto ser modelada como um processo dinâmico, pois opera a cada momento da produção do texto. Dessa maneira, a escolha de cada mensagem depende das mensagens anteriores, que passam a ser parte do contexto de situação, e das posteriores, às quais deve predizer (LEMKE, 1999), de forma que o acúmulo resultante do fluxo se torne um texto.

Por conta do acúmulo de significado, 'texto', 'produção de significado' e 'fluxo discursivo' depreendem o mesmo fenômeno. $\mathrm{O}$ 'texto' se refere ao produto final do acúmulo de significado; a 'produção de significado' às escolhas de funções nos sistemas para tomarem parte da unidade; e o 'fluxo discursivo' ao processo de produção e acumulação (Figura 1).
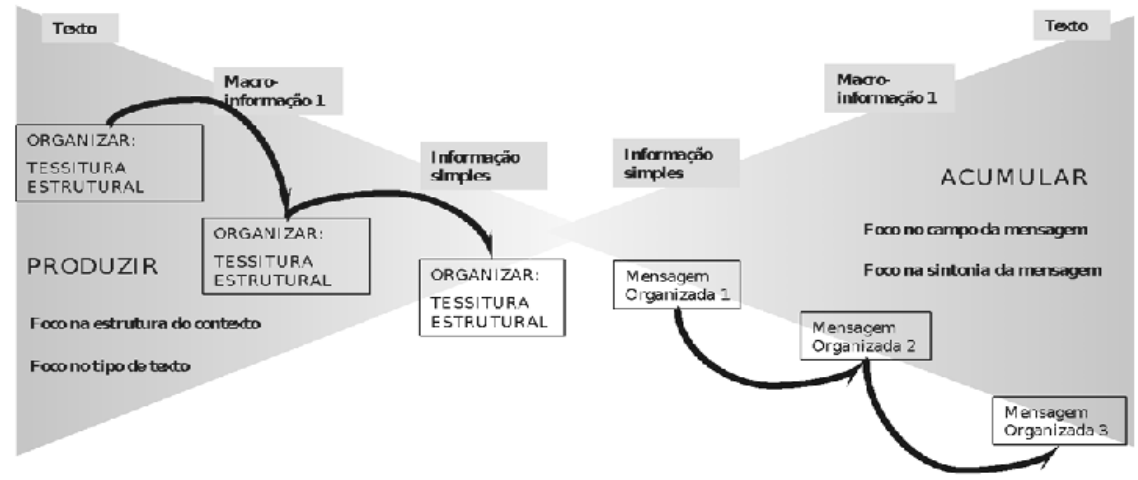

Figura 1. Produção de significado (adaptada de MARTIN, 1992, p. 456).

\subsection{A relação entre texto e gramática}

A relação entre texto e gramática remonta aos estudos de Mathesius, que distingue a oração como uma unidade gramatical, mas também como uma unidade semântica a partir da sua função no ato discursivo (o que neste artigo denomina-se 'mensagem'). A modelagem da organização dos sentidos como um único estrato da semântica discursiva, portanto, é capaz de explicar o papel duplo da oração na gramática e no discurso. Mathesius (1983) identifica na oração a função de Tema - aquilo sobre o quê o falante diz alguma coisa. Ainda relacionando a gramática à 
mensagem, Halliday (1970) aponta como o TEMA organiza as funções que realizam a MENSAGEM, bem como estas são empregadas pelo falante na apresentação da informação (ILARI, 1992). Tal emprego é ainda, dependente do tipo de texto (MATTHIESSEN, 1992).

Dinamicamente, o emprego sucessivo das mensagens, configura as estruturas do discurso (FRIES, 1981). Fries (1981) explica como a organização da oração por meio da seleção temática realiza diferentes tipos de relações entre as mensagens, evidenciando um padrão mais amplo que governa o fluxo discursivo. Esse padrão, denominado 'método de desenvolvimento' (FRIES, 1981), descreve as possibilidades de configurações estruturais das mensagens na composição do texto. Fries (1981) identifica as possibilidades de o Tema de uma oração ser retomado na oração seguinte [Tema2 = Tema1]; um Tema ser repetido ao longo do texto [Tema $=$ Tema1, Tema2, Tema3...]; ou, o Rema de uma oração ser o Tema da oração seguinte [Tema2 $=$ Rema1 $]$.

Seguindo o princípio de organização segundo o qual o TEMA gerencia a informação, as funções das mensagens também são capazes de distribuir a informação ao longo do fluxo em passagens do texto maiores que a oração denominadas hipermensagens e macromensagens (respectivamente, para uma fase do texto, e para o texto inteiro).

\section{METODOLOGIA}

A base para a metodologia foi retirada da teoria de descrição sistêmicofuncional (HALLIDAY, 1996), considerando-se, primeiramente, a noção de que não existe estrutura linguística (i.e., a ordenação da língua a partir do eixo sintagmático) que não seja motivada por uma escolha (i.e., a sistematização da língua a partir do eixo paradigmático) (SAUSSURE, 2006). Assim, a partir do eixo paradigmático, orienta-se a descrição de forma a modelar a estrutura como sendo a resultante final da produção linguística (MARTIN, 2013).

Em segundo lugar, considera-se a visão trinocular (HALLIDAY, 1996), a qual permite investigar um fenômeno linguístico contextualizado na estratificação. A partir das bases propostas para a metodologia, o objetivo da descrição pôde ser desdobrado em descrição "de baixo": indicando como os tipos de Tema realizam opções do sistema de MENSAGEM. Descrição "ao redor": apresentando a forma pela qual as opções do sistema de MENSAGEM se relacionam na rede do sistema. Descrição "de cima": explicando o papel das mensagens no mecanismo de acúmulo de significado, bem como esta estrutura o fluxo discursivo (Figura 2). 


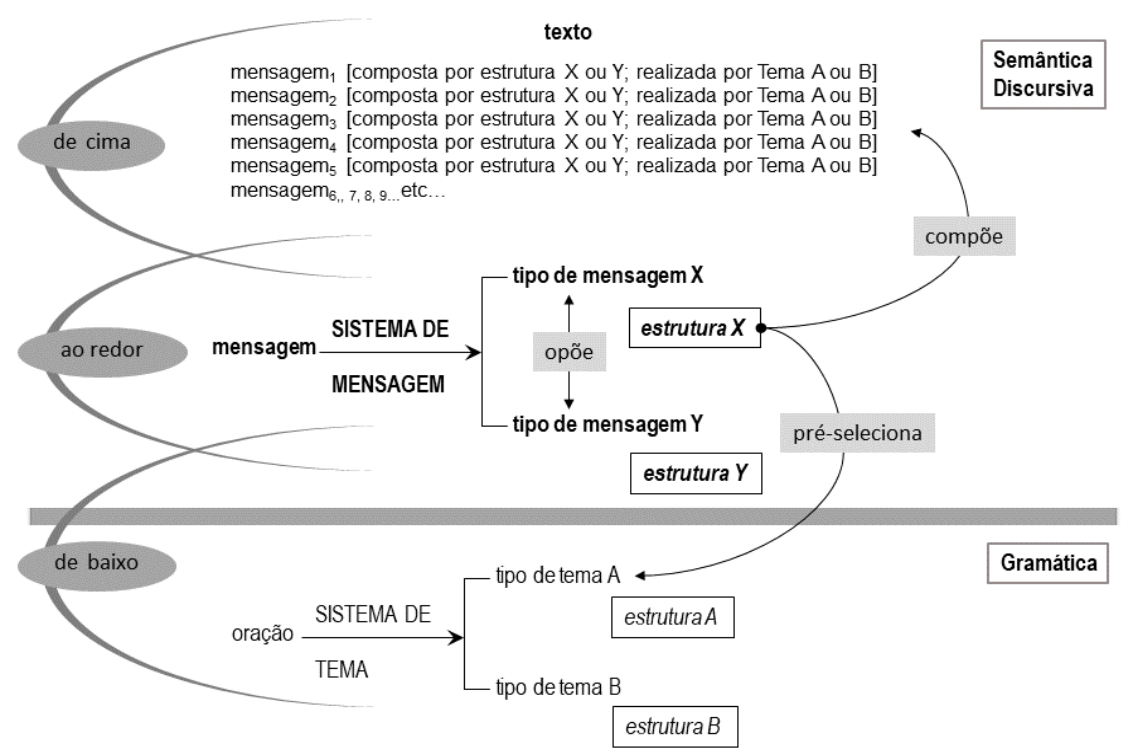

Figura 2. Visão trinocular de descrição da mensagem.

\subsection{Compilação do corpus}

O corpus CALIBRA (Catálogo da Língua Brasileira) foi utilizado como fonte da qual se extraiu a amostra de dados. Os textos foram compilados segundo os critérios da língua no contexto de cultura, que possibilitam uma tipologia com cinco variáveis: (1) Especialização: considera-se o texto no contínuo do conhecimento técnico, especializado para um determinado campo, e o leigo. (2) Situação: considera-se o texto como fundamental ou facilitador para a situação sócio-cultural (constitutivo/auxiliar). (3) Produção: considera-se o modo de produção original do texto (escrito/falado). (4) Interação: considera-se a relação estabelecida textualmente entre os interlocutores, pressupondo a expectativa de interação com o ouvinte (monólogo/diálogo). (5) Processo sócio-semiótico: considera-se a forma pela qual os textos estão dispersos no contexto de cultura, dividindo-se nos tipos explorar, explicar, relatar, recriar, compartilhar, fazer, recomendar ou habilitar (MATTHIESSEN et al, 2008).

Esta descrição utilizou 10\% do CALIBRA (100.099 tokens e 198 textos). Foram uma média de 12.501 tokens e 24,75 textos para cada processo sóciosemiótico, divididos entre os modos de produção e interação para cada tipo de texto (Tabela 1). 
Tabela 1. A constituição do corpus de pesquisa

\begin{tabular}{|c|c|c|c|c|c|c|c|}
\hline \multirow{2}{*}{$\begin{array}{l}\text { ESPECIA- } \\
\text { LIZAÇÃO }\end{array}$} & \multirow[b]{2}{*}{$\begin{array}{l}\text { PA- } \\
\text { PEL }\end{array}$} & \multirow[b]{2}{*}{$\begin{array}{c}\text { PRO- } \\
\text { CESSO }\end{array}$} & \multicolumn{2}{|c|}{ escrito } & \multicolumn{2}{|c|}{ falado } & \multirow[b]{2}{*}{ subtotais: } \\
\hline & & & diálogo & \multicolumn{2}{|c|}{ monólogo } & $\begin{array}{l}\text { diálo- } \\
\text { go }\end{array}$ & \\
\hline $\begin{array}{l}\text { especiali- } \\
\text { zada }\end{array}$ & \multirow{4}{*}{$\begin{array}{c}\text { cons- } \\
\text { tituti- } \\
\text { vo }\end{array}$} & $\begin{array}{l}\text { Expli- } \\
\text { car }\end{array}$ & $\begin{array}{l}6 \text { txts } \\
3130 \\
\text { tkns }\end{array}$ & $\begin{array}{l}6 \text { txts } \\
3133 \\
\text { tkns }\end{array}$ & $\begin{array}{l}5 \text { txts } \\
3165 \\
\text { tkns }\end{array}$ & $\begin{array}{l}4 \text { txts } \\
3142 \\
\text { tkns }\end{array}$ & $\begin{array}{l}21 \text { txts } \\
12.570 \\
\text { tkns }\end{array}$ \\
\hline \multirow{6}{*}{$\begin{array}{c}\text { não- } \\
\text { especializada }\end{array}$} & & Relatar & $\begin{array}{l}4 \text { txts } \\
3131 \\
\text { tkns }\end{array}$ & $\begin{array}{l}4 \text { txts } \\
3138 \\
\text { tkns }\end{array}$ & $\begin{array}{l}5 \text { txts } \\
3148 \\
\text { tkns }\end{array}$ & $\begin{array}{l}5 \text { txts } \\
3134 \\
\text { tkns }\end{array}$ & $\begin{array}{l}18 \text { txts } \\
12.551 \\
\text { tkns }\end{array}$ \\
\hline & & $\begin{array}{l}\text { Re- } \\
\text { criar }\end{array}$ & $\begin{array}{l}5 \text { txts } \\
3139 \\
\text { tkns }\end{array}$ & $\begin{array}{l}8 \text { txts } \\
3127 \\
\text { tkns }\end{array}$ & $\begin{array}{l}4 \text { txts } \\
3150 \\
\text { tkns }\end{array}$ & $\begin{array}{l}4 \text { txts } \\
3175 \\
\text { tkns }\end{array}$ & $\begin{array}{l}21 \text { txts } \\
12.591 \\
\text { tkns }\end{array}$ \\
\hline & & $\begin{array}{l}\text { Com- } \\
\text { parti- } \\
\text { lhar }\end{array}$ & $\begin{array}{l}6 \text { txts } \\
3093 \\
\text { tkns }\end{array}$ & $\begin{array}{l}7 \text { txts } \\
3125 \\
\text { tkns }\end{array}$ & $\begin{array}{l}4 \text { txts } \\
3191 \\
\text { tkns }\end{array}$ & $\begin{array}{l}5 \text { txts } \\
3122 \\
\text { tkns }\end{array}$ & $\begin{array}{l}22 \text { txts } \\
12.531 \\
\text { tkns }\end{array}$ \\
\hline & $\begin{array}{l}\text { auxi- } \\
\text { liar }\end{array}$ & Fazer & $\begin{array}{l}12 \text { txts } \\
3068 \\
\text { tkns }\end{array}$ & $\begin{array}{l}17 \text { txts } \\
3116 \\
\text { tkns }\end{array}$ & $\begin{array}{l}8 \text { txts } \\
3132 \\
\text { tkns }\end{array}$ & $\begin{array}{l}7 \text { txts } \\
3133 \\
\text { tkns }\end{array}$ & $\begin{array}{l}44 \text { txts } \\
12.449 \\
\text { tkns }\end{array}$ \\
\hline & \multirow{3}{*}{$\begin{array}{l}\text { cons- } \\
\text { tituti- } \\
\text { vo }\end{array}$} & $\begin{array}{l}\text { Reco- } \\
\text { men- } \\
\text { dar }\end{array}$ & $\begin{array}{l}5 \text { txts } \\
3164 \\
\text { tkns }\end{array}$ & $\begin{array}{l}8 \text { txts } \\
3112 \\
\text { tkns }\end{array}$ & $\begin{array}{l}5 \text { txts } \\
3102 \\
\text { tkns }\end{array}$ & $\begin{array}{l}4 \text { txts } \\
3153 \\
\text { tkns }\end{array}$ & $\begin{array}{l}22 \text { txts } \\
12.531 \\
\text { tkns }\end{array}$ \\
\hline & & $\begin{array}{l}\text { Capa- } \\
\text { citar }\end{array}$ & $\begin{array}{l}6 \text { txts } \\
3101 \\
\text { tkns }\end{array}$ & $\begin{array}{l}8 \text { txts } \\
3015 \\
\text { tkns }\end{array}$ & $\begin{array}{l}5 \text { txts } \\
3081 \\
\text { tkns }\end{array}$ & $\begin{array}{l}5 \text { txts } \\
3137 \\
\text { tkns }\end{array}$ & $\begin{array}{l}24 \text { txts } \\
12.334 \\
\text { tkns }\end{array}$ \\
\hline \multirow[t]{2}{*}{ especializada } & & $\begin{array}{c}\text { Explo- } \\
\text { rar }\end{array}$ & $\begin{array}{l}6 \text { txts } \\
3128 \\
\text { tkns }\end{array}$ & $\begin{array}{l}8 \text { txts } \\
3144 \\
\text { tkns }\end{array}$ & $\begin{array}{l}6 \text { txts } \\
3147 \\
\text { tkns }\end{array}$ & $\begin{array}{l}6 \text { txts } \\
3123 \\
\text { tkns }\end{array}$ & $\begin{array}{l}26 \text { txts } \\
12.542 \\
\text { tkns }\end{array}$ \\
\hline & \multicolumn{7}{|c|}{ total: 198 txts / 100.099 tkns } \\
\hline
\end{tabular}

\subsection{Etiquetamento e análise dos dados}

Para a identificação das estruturas funcionais das mensagens, os fatores considerados foram que as opções do sistema de MENSAGEM são realizadas por estruturas das mensagens. As estruturas, por sua vez, pré-selecionam no estrato abaixo opções do TEMA.

Para a identificação das estruturas oracionais que realizam a MENSAGEM foram executados os passos: (1) busca das realizações estruturais de orações independentes e paratáticas. (2) busca de padrões dos diferentes tipos de funções das mensagens. (3) Análise da distinção entre as diferentes configurações por meio de oposição de valeur e diferentes estruturas. (4) Caracterização de cada função específica. Após a identificação e separação das mensagens em diferentes tipos, (5) os dados foram extraídos como segmentos anotados e analisados segundo a visão trinocular. Esses passos foram executados de forma semi-automática, com o auxílio do software UAMTools (O’Donnell, 2007), o qual possibilita a anotação de estruturas linguísticas a partir de uma rede de sistemas. 


\section{O SISTEMA DE MENSAGEM}

\subsection{A MENSAGEM abordada "de baixo"}

Para dar início à abordagem da MENSAGEM "de baixo", cabe aqui uma breve apresentação do TEMA e sua pré-seleção, o que aqui será feito em relação ao PB (BÁRBARA; GOUVEIA, 2001; FIGUEREDO, 2011; ILARI, 1992). A pré-seleção é uma operação de realização que implica em uma opção sistêmica ser realizada por uma função de um sistema no estrato abaixo (HALLIDAY; MATTHIESSEN, 1999). Isto significa que, para cada opção da MENSAGEM, uma escolha anterior por uma determinada função de Tema já deve ter sido feita. Portanto, as diferentes configurações das funções temáticas das orações evidenciam «de baixo» os diferentes tipos de mensagem.

Na gramática, o papel principal do TEMA é gerenciar as funções geradas por sistemas ideacionais e interpessoais de forma que sejam convertidas em texto. A este processo dá-se o nome de semiotização. Por exemplo:

Exemplo 1 [FAZ_EM_02]:

(1) (a) eu vou retirar da água,

(b) e colocar aqui.

(c) Não coloque... uma posta em cima da outra.

O exemplo (1) traz três orações de um texto do processo sócio-semiótico Fazer/Falado/Monólogo e trata de um tutorial no qual a pessoa ensina uma receita de peixe e também faz o prato ao mesmo tempo. Esse tutorial é organizado como uma lista de procedimentos, nos quais a pessoa exerce impacto sobre os ingredientes para transformá-los. No texto, o impacto transformativo é representado por um conjunto de funções ideacionais. A primeira oração (1a) é da classe material, pois traz na estrutura a função de Processo Material: Transformativo, realizada pelo grupo verbal 〈vou retirar〉. Como Participantes neste Processo, tem-se o 〈eu〉 como Ator, e Meta a 〈posta de peixe〉, que está elíptica. O mesmo acontece para a oração (1b).

Ao mesmo tempo, a pessoa assume o papel do interlocutor que irá obedecer os procedimentos, encenada por um conjunto de funções interpessoais. A oração (1a) é declarativa, pois traz na estrutura as funções de Sujeito, realizado pelo grupo nominal 〈eu〉, que por sua vez cumpre o papel do interlocutor responsável pela proposição e o Finito 〈vou〉, que indica a obediência aos procedimentos (pois não está modalizado, avaliado ou polarizado; cf. 〈talvez vou〉; 〈posso ir〉; 〈não vou〉). $\mathrm{O}$ mesmo acontece para (1b).

Para que esse conjunto de funções de natureza distinta, Participante, Material, Meta, Sujeito, Finito possam fazer parte do texto, as funções devem ser apresentadas conforme o fluxo discursivo esperado para os textos do tipo Fazer/ Falado/Monólogo. Assim, nas orações (1a) e (1b), a informação apresentada parte do Ator no Processo Material: Transformativo, do ponto de vista ideacional e, concomitantemente, do ponto de vista interpessoal, parte do Sujeito. Com isso, o 
que se produz é uma confluência entre a informação escolhida para ser apresentada inicialmente, mais o Ator, e mais o Sujeito. É a essa operação de confluência que se dá o nome de 〈semiotização〉. Igualmente, é responsabilidade do TEMA fazer essa operação. Assim:

Exemplo 2:

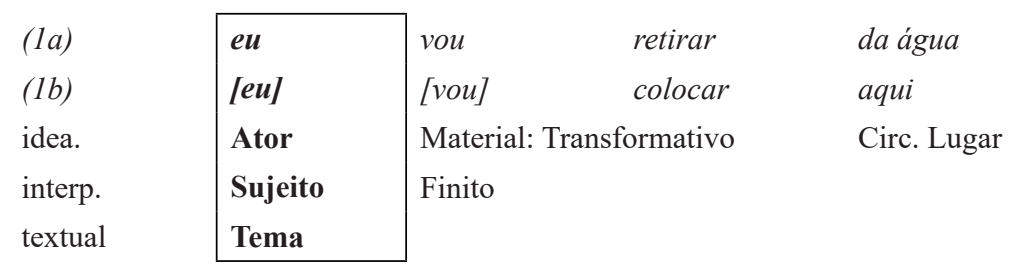

$\mathrm{Na}$ terceira oração (1c), contudo, ocorre uma divergência. Em (1c) a responsabilidade não recai sobre o interlocutor responsável por ensinar o procedimento, mas sim sobre aquele que irá fazer a receita. Por isso, ocorre uma mudança na oração da classe declarativa para a classe imperativa. O papel do TEMA é semiotizar esta mudança, o que apresenta a informação relevante fazendo com que conflua com o Sujeito da oração imperativa realizado pela elipse.

Exemplo 3:

\begin{tabular}{l|l|lll} 
(1c) & [Ø] & não & coloque & uma posta em cima da outra \\
idea. & Ator \\
interp. & Polaridade & Mat.:Transf. & Meta \\
textual & $\begin{array}{l}\text { Sujeito } \\
\text { Tema }\end{array}$ & & Predicador & \\
\cline { 2 - 3 } & & & &
\end{tabular}

O TEMa possui opções distintas que podem tanto apresentar confluências que sigam um determinado fluxo discursivo, como foi o caso do fluxo entre as orações (1a) e (1b), ou, alternativamente, que provoquem alguma mudança no fluxo como foi o caso da relação entre $(1 a+1 b)$ e (1c).

No caso de outras línguas, como chinês (HALLIDAY; MCDONALD, 2004), francês (CAFFAREL, 2006) e inglês (MATTHIESSEN, 1995), essas duas opções, de manter o fluxo e mudar o fluxo por meio da semiotização de funções na gramática, é caracterizado como os tipos de Tema não-marcado e marcado. Contudo, a partir da identificação do Tema em PB (BÁRBARA; GOUVEIA, 2001; ILARI, 1992), existe uma variação maior, na qual o fluxo pode sofrer mudanças parciais (apenas ideacionais, ou apenas interpessoais), em um contínuo que vai do menos marcado ao mais marcado (cf. ILARI, 1992; PONTES, 1987). Na oração (1c), por exemplo, a mudança foi apenas parcial - manutenção do Processo e mudança de Modo. Dessa maneira, existem quatro opções básicas (FIGUEREDO, 2011) na oração em PB: (1) manutenção ideacional e manutenção interpessoal - TEMA DEFAult. (2) Mudança ideacional e manutenção interpessoal - TEMA ELEMENTAL. (3) Manutenção ideacional e mudança interpessoal TEMA ângulo. (4) Mudança ideacional e mudança interpessoal - TEMA PROEMINENTE. 
O TEXTO 1, apresentado a seguir, mostra como o emprego de diferentes opções do TEMA indicam diferenças nos tipos de mensagem. O texto é um procedimento, extraído do manual do SEBRAE que trata do ensacamento de farinha. Mais especificamente, tem como propósito dar proeminência para as etapas do ensacamento.

Texto 1 [XPL_EM_16]:

\begin{tabular}{|c|c|c|}
\hline & Tema & Rema \\
\hline 1 & $\begin{array}{l}\text { Ensacamento } \\
\text { Absoluto: Ente Abstração }\end{array}$ & \\
\hline 2 & $\begin{array}{l}\text { Antes do ensacamento } \\
\text { Tema: Proeminente: Perspectiva }\end{array}$ & a farinha deve ser classificada. \\
\hline 3 & $\begin{array}{l}\text { A classificação } \\
\text { Tema: Default }\end{array}$ & $\begin{array}{l}\text { será conforme a demanda do mercado consumi- } \\
\text { dor. }\end{array}$ \\
\hline 4 & $\begin{array}{l}\text { Para isto } \\
\text { Tema: Textual \& Proeminente: Pers- } \\
\text { pectiva }\end{array}$ & $\begin{array}{l}\text { existem conjuntos de peneiras de diferentes tama- } \\
\text { nhos de malha. }\end{array}$ \\
\hline 5 & $\begin{array}{l}\text { Durante a classificação } \\
\text { Tema: Proeminente: Perspectiva }\end{array}$ & $\begin{array}{l}\text { o movimento da peneira gera grande quantidade } \\
\text { de pó. }\end{array}$ \\
\hline 6 & $\begin{array}{l}\text { Nesta etapa } \\
\text { Tema: Textual \& Proeminente: Pers- } \\
\text { pectiva }\end{array}$ & $\begin{array}{l}\text { é indispensável o uso de equipamento de proteção } \\
\text { respiratória. }\end{array}$ \\
\hline 7 & $\begin{array}{l}\text { A farinha } \\
\text { Tema: Default }\end{array}$ & $\begin{array}{l}\text { poderá ser acondicionada em sacos de ráfia com } \\
\text { capacidade para } 50 \mathrm{Kg} \text { ou em pacotes de } 1 \mathrm{Kg} \text {, }\end{array}$ \\
\hline 8 & $\begin{array}{l}\text { esta última } \\
\text { Tema: Default }\end{array}$ & $\begin{array}{l}\text { preferencialmente deve ser feita através de ensa- } \\
\text { cadeiras automáticas que evitam o manuseio do } \\
\text { produto acabado. }\end{array}$ \\
\hline 9 & $\begin{array}{l}\text { Para os sacos com } 50 \mathrm{Kg} \\
\text { Tema: Proeminente: Perspectiva }\end{array}$ & $\begin{array}{l}\text { existem dois tipos de procedimento: enchimento } \\
\text { mecânico e fechamento com costuradeira elétrica } \\
\text { e enchimento e costura manual. }\end{array}$ \\
\hline 10 & $\begin{array}{l}\text { Nesta etapa } \\
\text { Tema: Textual \& Proeminente: Pers- } \\
\text { pectiva }\end{array}$ & $\begin{array}{l}\text { a geração de resíduos sólidos é proveniente das } \\
\text { embalagens danificadas, que devem ser acondi- } \\
\text { cionadas em fardos para uma posterior reutiliza- } \\
\text { ção ou venda. }\end{array}$ \\
\hline 11 & $\begin{array}{l}\text { No enchimento dos sacos } \\
\text { Tema: Proeminente: Perspectiva }\end{array}$ & existe a emissão de particulados. \\
\hline 12 & $\begin{array}{l}\text { Nesta etapa } \\
\text { Tema: Textual \& Proeminente: Pers- } \\
\text { pectiva }\end{array}$ & deve-se garantir uma boa ventilação no local \\
\hline
\end{tabular}




\begin{tabular}{|l|l|l|}
\hline 13 & $\begin{array}{l}\text { e, também, recomenda-se } \\
\text { Tema: } \text { Default }\end{array}$ & o uso de equipamento de proteção respiratória. \\
\hline 14 & $\begin{array}{l}\text { Como nas etapas anteriores } \\
\text { Tema: Proeminente: Perspectiva }\end{array}$ & $\begin{array}{l}\text { deve ser observado o uso correto da energia elé- } \\
\text { trica. }\end{array}$ \\
\hline
\end{tabular}

As atividades no TEXTO 1 são sequenciadas a partir de relações temporais e causais. Por exemplo, nas mensagens (2) temporal, ou (12) causal. As mensagens que semiotizam essa sequência de atividades pré-selecionam as funções de Tema: Proeminente: Perspectiva. Com isso, colocam-se em oposição a outras mensagens, realizadas por outros tipos de Tema, como por exemplo a função Tema: Absoluto na mensagem (1). Do ponto de vista interpessoal, há duas negociações importantes - a forma como o ensacamento deve ocorrer de acordo com o SEBRAE e as instruções de segurança. Por exemplo (7) e (13), com a pré-seleção de Tema: Default.

Por conseguinte, o exame "de baixo" da mensagem permite compreender que as funções do Tema se caracterizam, na verdade, como as formas de préseleção que realizam diferentes tipos de mensagem. Assim, a partir do TEXTO 1, é possível identificar um tipo de mensagem que pré-seleciona a sequência de atividades relativos a tempo e causa, realizados por Tema: Proeminente, e outra para a negociação, realizados por Tema: Default (Figura 3).

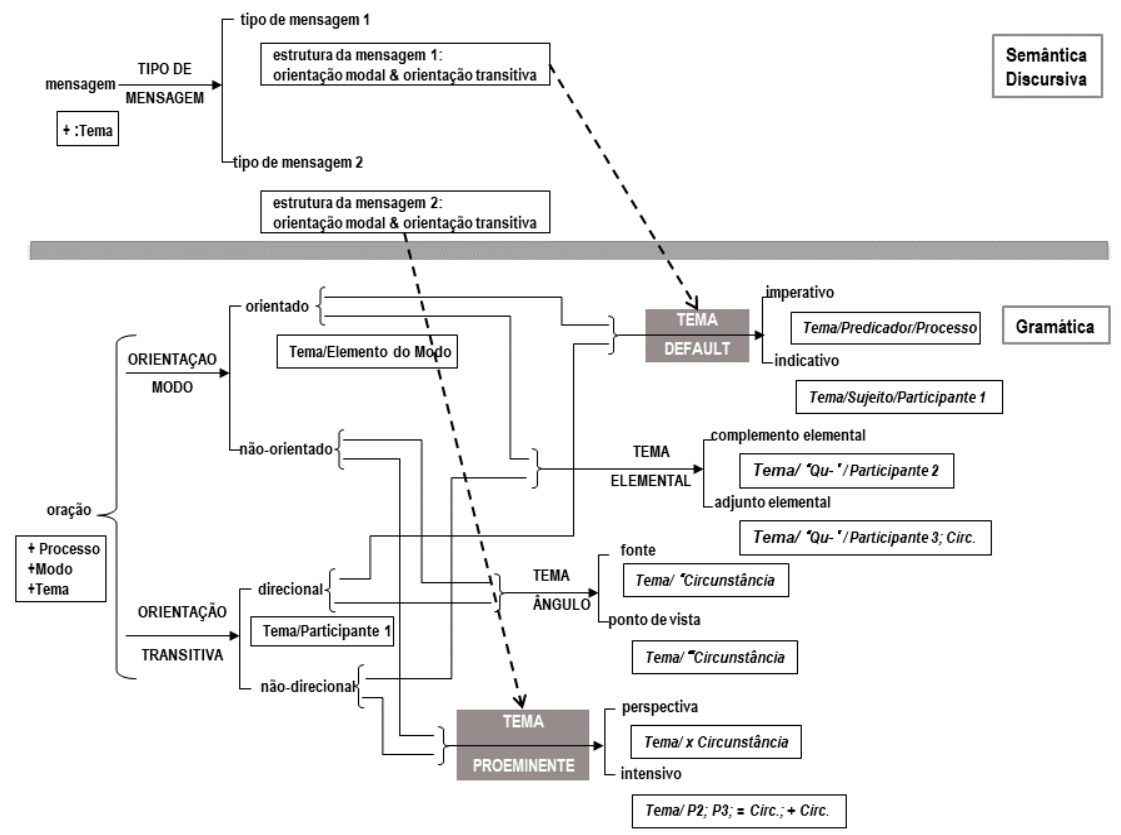

Figura 3. Pré-seleção da MENSAGEM “de baixo" pelas funções do Tema no TEXTO 1. 
Uma característica geral dessa pré-seleção é que o contraste entre escolhas por diferentes tipos de Tema indica alguma mudança no fluxo. A sucessão de escolhas temáticas revela que a organização das mensagens orienta o fluxo discursivo para a semiotização dos significados ideacionais e interpessoais a partir da estrutura do contexto. Este processo é denominado 'contextualização'. A contextualização será examinada com mais detalhe na seção seguinte.

\subsection{A MENSAGEM abordada "ao redor"}

Os significados de contextualização constituem as opções mais gerais do sistema de MENSAGEM. Com isso, a contextualização também estabelece as fases do discurso - tanto para dar início, quanto para concluir a fase. A fase é identificada quando o campo e a sintonia se conservam ao longo do texto, e constroem um macro-significado que faz parte de um mesmo tópico. O tópico é definido como o conjunto de informações proeminentes de uma fase (MARTIN, 1992).

A opção sistêmica [tópico] dá início a uma fase, e é frequentemente realizada por uma oração no início da estrutura da fase com Tema: Default, uma vez que estabelece no Tema o elemento principal que pré-seleciona o $\mathrm{P} 1$ e responde pela proposição, pré-selecionando o Sujeito. O Novo da oração que a realiza ganha a proeminência na distribuição de informação através da opção [apresentar] do sistema de IDENTIFICAÇÃo. O [tópico] pode ainda ser uma entidade realizada pela função Ente: Abstração do grupo nominal - como é o caso do TEXTO 1, com (1) 'Ensacamento'.

A mensagem final acumula o significado da fase de forma a concluí-la, ou a anunciar a próxima fase. Esta é a opção [culminativa], realizada na oração pela pré-seleção de um Tema: Default e o Novo de opção [presumir] do sistema de IDENTIFICAÇÃo. Ela pode promover uma mudança para que este retome a fase inteira, de maneira generalizada. Neste caso, é realizada por um Tema: Proeminente confluído com o Novo.

No caso do TEXTO 1, a mensagem (6) 'Nesta etapa é indispensável...' realiza a [culminativa], uma vez que traz no Tema a fase generalizada 'Nesta etapa', realizada pelo Tema: Proeminente e, no Novo, a confluência com a opção [presumir], que trata justamente do pré-ensacamento. Uma vez iniciada a fase que dá início à contextualização, pode haver outras mensagens que a seguem. Por exemplo, a mensagem (2) desenvolve a fase do pré-ensacamento (Figura 4).

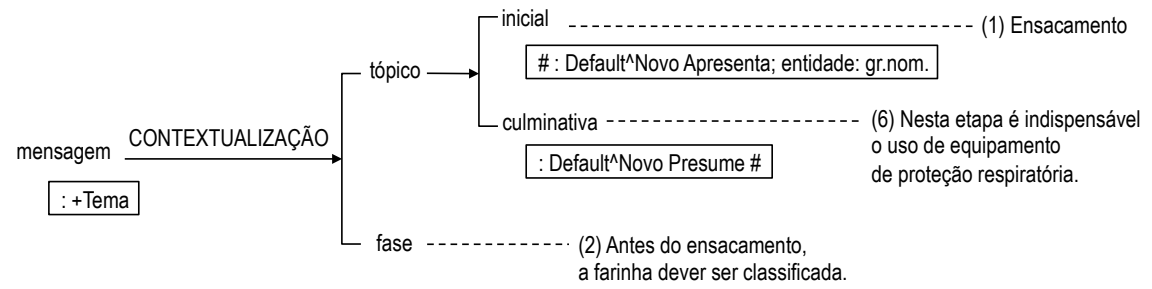

Figura 4. O sistema de CONTEXTUALIZAÇÃo. 
Dentro de uma mesma fase, uma mensagem pode ampliar o significado da anterior, desenvolvendo o campo e reforçando a sintonia. Esta mensagem realiza a opção [continuidade] (MARTIN; ROSE, 2007, p. 191). A [continuidade] semiotiza os mesmos significados ideacionais e interpessoais das mensagens que a precedem, podendo elaborá-las ou estendê-las. Gramaticalmente, possuem os mesmos Temas das orações anteriores, ou Tema: Textual com elemento referencial que recupera o Tema das orações anteriores, e Dado confluindo com a opção [presumir], que se desenvolvem nos padrões de método de desenvolvimento identificados por Fries (1983). Para a [elaboração], o método é [T2 = T1] e [T = T1, T2, etc.]; na [extensão], é T2 = R1.

No TEXTO 1, o significado que realiza o campo e a sintonia da fase iniciada pela mensagem 1 é estendido pela mensagem 2. Desta forma, a mensagem 2 realiza a [continuidade]. Neste caso, os significados de Processo/Predicador «ser classificada〉 da mensagem 2 foram novamente semiotizados na mensagem 3 como Tema: Default e Dado e presumir 〈A classificação〉, com T2=R1. A opção de continuidade está presente em outras partes do texto (Quadro 1).

Quadro 1. Exemplos de continuidade no TEXTO 1.

\begin{tabular}{|l|l|l|}
\hline & mensagem 1 & mensagem 2 \\
\hline 1 & $\begin{array}{l}\text { A classificação será conforme a demanda } \\
\text { do mercado consumidor. }\end{array}$ & $\begin{array}{l}\text { Para isto [T2 }=\mathrm{T} 1] \text { existem conjuntos de penei- } \\
\text { ras de diferentes tamanhos de malha. } \\
\text { mensagem: } \text { continuidade: } \text { elaboração }\end{array}$ \\
\hline 2 & $\begin{array}{l}\text { Durante a classificação o movimento da } \\
\text { peneira gera grande quantidade de pó. }\end{array}$ & $\begin{array}{l}\text { Nesta etapa [T2 = T1] é indispensável o uso de } \\
\text { equipamento de proteção respiratória. } \\
\text { mensagem: } \text { continuidade: } \text { elaboração }\end{array}$ \\
\hline 3 & $\begin{array}{l}\text { Para os sacos com 50Kg existem dois tipos } \\
\text { de procedimento: enchimento mecânico e } \\
\text { fechamento com costuradeira elétrica e en- } \\
\text { chimento e costura manual. }\end{array}$ & $\begin{array}{l}\text { Nesta etapa [T2 }=\text { R1] a geração de resíduos só- } \\
\text { lidos é proveniente das embalagens danificadas, } \\
\text { que devem ser acondicionadas em fardos para } \\
\text { uma posterior reutilização ou venda. } \\
\text { mensagem: } \text { continuidade: } \text { extensãa }\end{array}$ \\
\hline 4 & $\begin{array}{l}\text { No enchimento dos sacos existe a emissão } \\
\text { de particulados. }\end{array}$ & $\begin{array}{l}\text { Nesta etapa [T2 }=\text { T1] deve-se garantir uma boa } \\
\text { ventilação no local e, também, recomenda-se o } \\
\text { uso de equipamento de proteção. } \\
\text { mensagem: } \text { continuidade: } \text { elaboração }\end{array}$ \\
\hline
\end{tabular}

Uma mensagem pode, de outra forma, selecionar a [descontinuidade] na fase (MARTIN; ROSE, 2007). Para apresentar os recursos de [descontinuidade], apresenta-se o TEXTO 2: 
Texto 2 [EXP_FD_01]

\begin{tabular}{|c|c|c|c|}
\hline & \multicolumn{2}{|c|}{ Tema } & \multirow{2}{*}{$\begin{array}{l}\text { Rema } \\
\qquad \begin{array}{l}\text { é um fato típico ilícito e } \\
\text { culpável. }\end{array}\end{array}$} \\
\hline 1 & \multicolumn{2}{|l|}{$\begin{array}{l}\text { Crime } \\
\text { Default }\end{array}$} & \\
\hline 2 & $\begin{array}{l}\text { bom nós temos que } \\
\text { entender o seguinte na } \\
\text { verdade } \\
\text { Textual }\end{array}$ & $\begin{array}{l}\text { o crime } \\
\text { Intensivo: Proj.: Assunto }\end{array}$ & $\begin{array}{l}\text { ele é um fato único está mas } \\
\text { ah... é um fato único }\end{array}$ \\
\hline 3 & $\begin{array}{l}\text { mas } \\
\text { Textual }\end{array}$ & $\begin{array}{l}\text { nós } \\
\text { Default }\end{array}$ & $\begin{array}{l}\text { vamos ver esses elementos } \\
\text { separadamente por uma questão } \\
\text { metodológica e por uma questão } \\
\text { de análise }\end{array}$ \\
\hline 4 & \multicolumn{2}{|l|}{$\begin{array}{l}\text { por isso que } \\
\text { Textual/Perspectiva }\end{array}$} & $\begin{array}{l}\text { é a teoria analítica do } \\
\text { crime: tipicidade ilicitude e } \\
\text { culpabilidade }\end{array}$ \\
\hline 5 & \multicolumn{2}{|c|}{$\begin{array}{l}\text { o crime } \\
\text { Intensivo: Projeção: Assunto }\end{array}$} & $\begin{array}{l}\text { eh... vamos imaginar com se } \\
\text { fosse uma rocha, entendeu? }\end{array}$ \\
\hline 6 & $\begin{array}{l}\text { e } \\
\text { Textual }\end{array}$ & $\begin{array}{l}\text { essa rocha } \\
\text { Intensivo: Proj.: Assunto }\end{array}$ & $\begin{array}{l}\text { se você pudesse pegar uma } \\
\text { serra e partir essa rocha ao meio } \\
\text { como se parte uma laranja, } \\
\text { entendeu? }\end{array}$ \\
\hline 7 & Textual & $\begin{array}{l}\text { quando você olha para o } \\
\text { interior da rocha } \\
\text { Perspectiva: Condição }\end{array}$ & você vê ali eh... três camadas \\
\hline 8 & $\begin{array}{l}\text { não é que } \\
\text { Interpessoal }\end{array}$ & $\begin{array}{l}\text { compõem } \\
\text { Intensivo: Processo }\end{array}$ & $\begin{array}{l}\text { aquela rocha os três tipos de } \\
\text { elementos que compõem aquela } \\
\text { rocha }\end{array}$ \\
\hline 9 & $\begin{array}{l}\text { na verdade } \\
\text { Textual }\end{array}$ & $\begin{array}{l}\text { o que eu quero dizer com este } \\
\text { exemplo } \\
\text { Default }\end{array}$ & $\begin{array}{l}\text { os elementos não existem por si } \\
\text { mesmos }\end{array}$ \\
\hline 10 & $\begin{array}{l}\text { os elementos } \\
\text { Default }\end{array}$ & & não existem sozinhos não \\
\hline
\end{tabular}

$\mathrm{Na}$ [descontinuidade], mensagem pode se concentrar em um aspecto específico da fase, alterando a perspectiva para o campo ou a sintonia da fase como um todo (i.e., global) - denominada [desvio]; ou ainda mudar o padrão de semiotização dos significados ideacionais e interpessoais específicos da mensagem em contraste ou foco em relação ao restante da fase (i.e., local) - denominada [mudança]. As mensagens que realizam a opção [descontinuidade: desvio] conservam significados ideacionais e interpessoais com as mensagens anteriores, porém apresentam também elementos distintos. $\mathrm{O}$ [desvio] é, em geral, realizado por Tema: Perspectiva em confluência com o Novo. No TEXTO 2, por exemplo, temos: 
Exemplo 4 [EXP_FD_01]:

(4) (a) e essa rocha se você pudesse pegar uma serra e partir essa rocha ao meio como se parte uma laranja, entendeu?,

(b) quando você olha para o interior da rocha, você vê ali eh... três camadas.

Nesta parte do texto, o falante explica como a rocha se divide em camadas. Ao desenvolver as atividades do campo, o falante passa a se concentrar em um aspecto específico desse - o "momento em que se olha para o interior da rocha". $\mathrm{O}$ falante se atém às camadas da rocha, mas modifica o fluxo apenas para essa condição. Assim, emprega na gramática um Tema: Perspectiva: Condicional, como pré-seleção para a mensagem que por sua vez realiza a opção [desvio] (Quadro 2).

Quadro 2. Exemplos de descontinuidade: desvio nos TEXTOS 1 e 2.

\begin{tabular}{|l|l|l|}
\hline & mensagem 1 & mensagem 2 \\
\hline 1 & $\begin{array}{l}\text { essa rocha, se você pudesse pegar uma } \\
\text { serra e partir essa rocha ao meio como se } \\
\text { parte uma laranja, entendeu? }\end{array}$ & $\begin{array}{l}\text { quando você olha para o interior da rocha você } \\
\text { mensagem: descontinuidade: desvio }\end{array}$ \\
\hline 2 & $\begin{array}{l}\text { Para isto existem conjuntos de peneiras de } \\
\text { diferentes tamanhos de malha. }\end{array}$ & $\begin{array}{l}\text { Durante a classificação o movimento da peneira } \\
\text { gera grande quantidade de pó. } \\
\text { mensagem: } \text { descontinuidade: } \text { desvio }\end{array}$ \\
\hline 3 & $\begin{array}{l}\text { Nós vamos ver esses elementos separada- } \\
\text { mente por uma questão metodológica e por } \\
\text { uma questão de análise }\end{array}$ & $\begin{array}{l}\text { por isso que é a teoria analítica do crime: tipici- } \\
\text { dade ilicitude e culpabilidade } \\
\text { mensagem: descontinuidade: } \text { desvio }\end{array}$ \\
\hline
\end{tabular}

Em outro caso, a mensagem pertence à mesma fase do discurso, mas é organizada a partir de elementos ideacionais e interpessoais diferentes das mensagens anteriores. Neste caso, a descontinuidade acontece pela diferença na forma de organização do campo ou sintonia da mensagem. Esta é a opção de [descontinuidade: mudança].

A [mudança] é selecionada quando uma mesma fase do discurso é constituída por conjuntos de eventos distintos. Em geral, a mudança é realizada por Tema: Intensivo, o que implica em uma reconfiguração da relação entre funções ideacionais e interpessoais (por exemplo: Ator/Sujeito + Meta/Complemento; Meta/Sujeito + Ator/Complemento), funções textuais que não confluem com funções ideacionais ou interpessoais (Absolutos), Circunstâncias de Elaboração, Extensão ou Projeção, sempre confluindo com o Novo do sistema de INFORMAÇÃo. No TEXTO 2:

Quadro 3. Exemplos de descontinuidade: mudança no TEXTO 2.

\begin{tabular}{|l|l|l|}
\hline & mensagem 1 & mensagem 2 \\
\hline 1 & $\begin{array}{l}\text { por isso que é a teoria analítica do crime: } \\
\text { tipicidade ilicitude e culpabilidade }\end{array}$ & $\begin{array}{l}\text { o crime, eh... vamos imaginar com se fosse uma } \\
\text { rocha, entendeu? } \\
\text { mensagem: } \text { descontinuidade: } \text { mudança }\end{array}$ \\
\hline
\end{tabular}




\begin{tabular}{|l|l|l|}
\hline 2 & $\begin{array}{l}\text { o crime, eh... vamos imaginar com se fosse } \\
\text { uma rocha, entendeu? }\end{array}$ & $\begin{array}{l}\text { e essa rocha, se você pudesse pegar uma serra } \\
\text { e partir essa rocha ao meio como se parte uma } \\
\text { laranja, entendeu? } \\
\text { mensagem: descontinuidade: } \text { mudança }\end{array}$ \\
\hline 3 & $\begin{array}{l}\text { esta última preferencialmente deve ser feita } \\
\text { através de ensacadeiras automáticas que } \\
\text { evitam o manuseio do produto acabado. }\end{array}$ & $\begin{array}{l}\text { Para os sacos com } 50 \mathrm{Kg} \text { existem dois tipos de } \\
\text { procedimento: enchimento mecânico e fecha- } \\
\text { mento com costuradeira elétrica e enchimento e } \\
\text { costura manual. } \\
\text { mensagem: } \text { descontinuidade: } \text { mudança }\end{array}$ \\
\hline
\end{tabular}

Em todas estas mensagens, a fase do discurso se mantém. Contudo, algum aspecto do fluxo é focalizado, no momento em que este é estruturado pela mensagem de mudança. A partir destas novas opções, podemos ampliar a contextualização incluindo as opções da FASE (Figura 5).

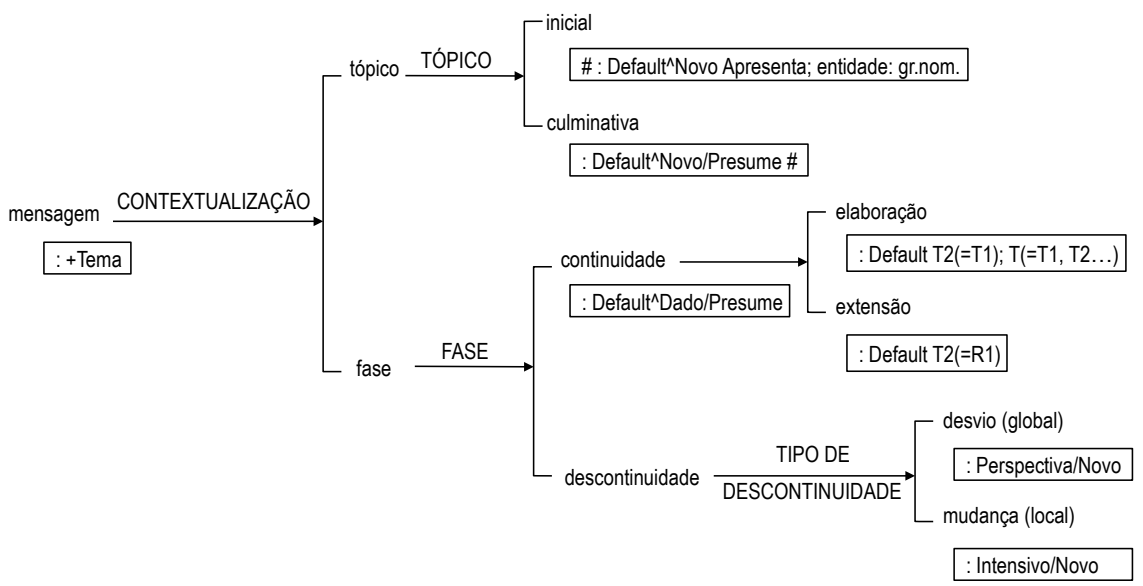

Figura 5. O sistema de FASE.

\subsection{A MENSAGEM abordada "de cima": o sistema de MENSAGEM: ARRANJO}

O arranjo é definido como o modo pelo qual o fluxo discursivo se agrupa em porções de mensagens que mantêm entre si maior semelhança, conferindo ao texto um caráter periódico. A periodicidade é o modelo empregado para descrever as fases do discurso (MARTIN e Rose, 2007).

Ao longo da construção textual há diferentes níveis nos quais a periodicidade se forma (Pike, 1982; Halliday, 1996). MARTIN (1992) apresenta os períodos que operam nas fases, identificados como hipermensagens e incluem a função de hiperTema, pois estabelecem o modo como acontece o arranjo ao longo de uma determinada fase. Aqueles que operam no nível do texto, as macromensagens, incluem a função de macroTema e estabelecem o arranjo em todo o texto.

A primeira opção do sistema de ARRANJO determina o desenvolvimento do fluxo discursivo - denominada [arranjamento]. A mensagem que realiza o [arranjamento] é empregada no texto para prenunciar as mensagens que estão por 
vir, e por isto corresponde ao início do período - que em geral é a macromensagem. A segunda opção do ARRANJAMENTO segue o desenvolvimento estabelecido denominada [arranjo default]. As mensagens de [arranjo default] pertencem ao mesmo período - subordinadas à mensagem com função de arranjamento.

Como exemplo, apresentamos o TEXTO 3, que é uma discussão entre políticos sobre o salário mínimo. O texto está analisado conforme as periodicidade e as opções do ARRANJAMENTO.

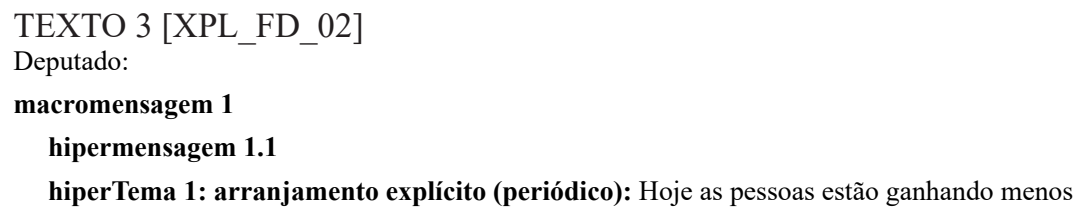

\section{hipermensagem 2.2}

hiperTema 10: arranjo default: Ouvi V. Exa. o tempo todo. mensagem 11: arranjo default: Só tenho 3 minutos. mensagem 12: arranjo default: V.Exa. falou durante 45 minutos mensagem 13: arranjo default: e ouvi V.Exa., durante o tempo todo, absolutamente calado.

OTEXTO3 é dividido entre a fala do deputado sobre o salário (macromensagem 1) e a discussão sobre a tomada de turno do ministro (macromensagem 2). A fala do deputado, por sua vez, se divide ainda em argumentação sobre a diminuição do salário (hipermensagem 1.1) e informação extra (hipermensagem 1.2). Já a tomada de turno se subdivide nos períodos de interrupção do ministro (hipermensagem 2.1) e resposta do deputado (hipermensagem 2.2). Dessa maneira, o ARRANJO seleciona [arranjamento] para as mensagens que dão início às macromensagens e [arranjo default] para as outras mensagens.

$\mathrm{O}$ [arranjamento] é ainda condição de entrada para um sistema mais delicado, denominado ARRANJAMENTO (Figura 6). O fluxo discursivo pode acontecer 
de forma 'explícita' ou periódica, quando é possível determinar quais são os macroTemas e como estes subordinam o restante do período - como é o caso do TEXTO 3. De outra forma, pode acontecer de forma 'implícita' ou em série, que se limita ao encadeamento de mensagens (MARTIN e Rose, 2007). Nesse caso, a relação entre as mensagens no fluxo discursivo não é sinalizada, e deve ser inferida pelo ouvinte. Como exemplo citam-se listas, leis, procedimentos, para os quais não existe uma organização mais ampla.

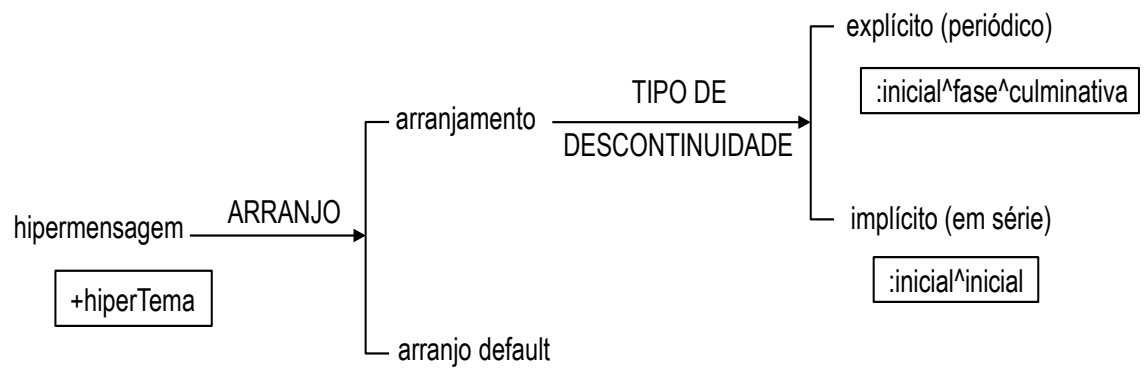

Figura 6. O sistema de ARRANJO.

A partir dos sistemas que geram as mensagens, é possível descrever a forma pela qual o fluxo discursivo se desenvolve, bem como os textos caracteristicamente apresentam um período de informação que subordina períodos menores, o que se, na semântica discursiva, por meio da cosseleção entre os sistemas de CONTEXTUALIZAÇÃo e ARRANJo (Figura 7). 


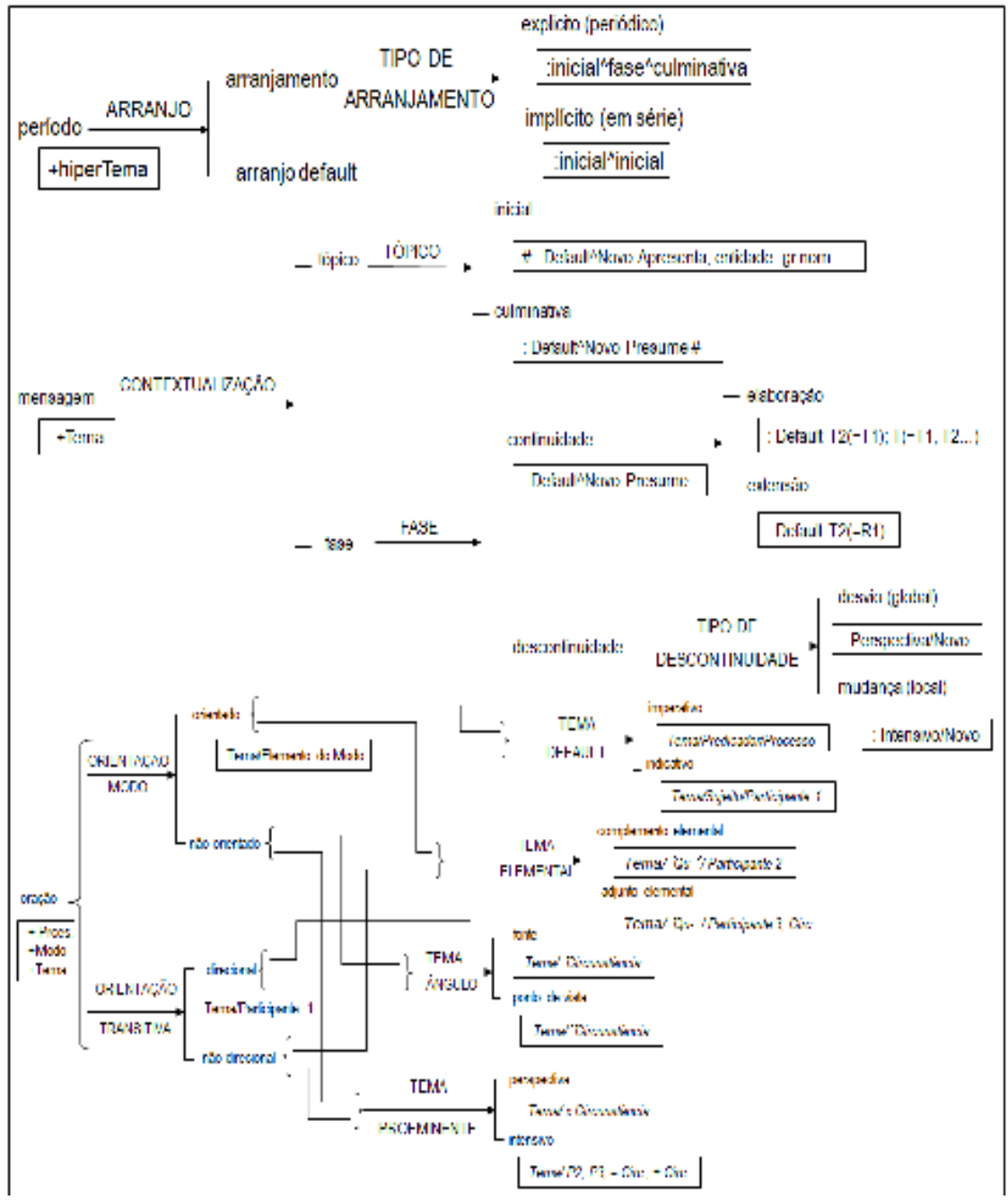

Figura 7. Periodicidade.

\section{CONSIDERAÇÕES FINAIS}

Estudos anteriores ao presente artigo mostram como a estrutura do texto é composta por funções que extrapolam a oração e formam uma unidade discursiva mais complexa, que vai para além da oração. Contudo, a literatura (FRIES, 1981; ILARI, 1992; KOCH, 2006; MARTIN, 1992; MARTIN; ROSE, 2007) não aponta 
de forma completa como o discurso se relaciona com a gramática no que diz respeito ao sistema discursivo textual que é realizado pelas orações. A falta da descrição completa dos sistemas textuais que organizam o fluxo do discurso gera problemas para a explicação da relação entre a semântica discursiva e a gramática, como por exemplo na forma como diferentes tipos de texto (portanto diferentes fluxos) demandam escolhas gramaticais diferentes. Várias correlações entre tipos de fluxo e escolhas gramaticais foram apontados em diversos estudos, contudo uma relação causal entre estes carece da descrição de sistemas semântico-discursivos que geram o fluxo.

Tendo o intuito de contribuir com este problema, o artigo teve como objetivo apresentar uma descrição do sistema de MENSAGEM, tomando como ponto de partida o conceito de que um texto não é apenas um conjunto de orações, mas um fluxo discursivo gerado pela MENSAGEM que, por sua vez, é um sistema realizado por pré-seleção de funções do sistema de TEMA na gramática da oração.

Partindo da hipótese de que o sistema de MENSAGEM organiza textualmente o fluxo discursivo, o artigo utilizou como base teórica a linguística sistêmicofuncional, segundo a qual a organização sistêmica da língua tem precedência sobre a sua estruturação. Dando maior foco à organização sistêmica, o artigo pôde então conduzir a descrição a partir de uma propriedade fundamental dos sistemas, que é a oposição entre opções que lhes confere valor. Esta propriedade foi então investigada a partir da visão trinocular.

A descrição do sistema "de baixo" revelou como diferentes opções de mensagem pré-selecionam funções diferentes de Tema. Desta forma, as mudanças no fluxo discursivo são capazes de explicar mudanças na progressão temática e no método de desenvolvimento.

A descrição «ao redor» apresentou o sistema de ConteXtualização. As opções desse sistema servem para dar significado à organização textual de cada MENSAGEM a partir de sua contextualização local, segundo sua organização interna, portanto a partir da gramática. Do ponto de vista da contextualização, a unidade de análise mais importante é a MENSAGEM. Isto porque cada nova MENSAGEM de um texto deve cumprir a função de iniciar, continuar, provocar desvio, mudança ou foco em uma fase do discurso. Quando uma MENSAGEM é contextualizada, ela é incorporada ao texto de forma a dar algum direcionamento à fase que pertence.

A descrição "de cima" apresentou o sistema de ARRANJO, cujas opções servem para realizar linguisticamente as etapas do tipo de texto, relativo a um contexto de situação, a partir do macro-significado de todo o texto. Isto significa que o ARRANJO lida com a semântica "de cima"; a partir do contexto para o discurso. Do ponto de vista do arranjo, a unidade de análise mais importante é o texto. Isto porque o fluxo discursivo deve se desenvolver e se dividir nas fases necessárias para acumular a informação do texto como um todo.

Desta forma, foi possível compreender que uma MENSAGEM, para tomar parte no texto, é gerada pelo sistema de MENSAGEM como a cosseleção de uma função de CONTEXTUALIZAÇÃO e ARRANJO. Igualmente, foi possível compreender como cada um dos sistemas contribui complementando as funções dos outros. 


\section{REFERÊNCIAS}

BARBARA, L.; GOUVEIA, C. It is not there, but [it] is cohesive: the case of pronominal ellipsis of subject in Portuguese. Direct Papers, São Paulo, n. 46, jul. 2001.

CAFFAREL, A. A systemic functional approach to grammar of French: from grammar to discourse. London: Continuum, 2006.

DANEŠ, F. Prague school functionalism as a precursor of text linguistics. Cahiers de l'ILSL, Lausanne, n. 5, p. 117-126, 1994.

van DIJK, T. Connectives in text grammar and text logic. In: van DIJK, T; PETOFI, J. (Ed.). Grammars and Descriptions. Berlin: De Gruyter, 1977.

FIRBAS, J. On defining the theme in english, german and czech. Brno Studies in English, Brno, n. 1, p. 39-63, 1964.

FÁVERO, L. Coesão e coerência textuais. São Paulo: Ática, 1991.

FIGUEREDO, G. Introdução ao perfil metafuncional do português brasileiro: contribuições para os estudos multilingues. 2011. 385 f. Tese (Doutorado em Linguística Aplicada) - Universidade Federal de Minas Gerais, Belo Horizonte, 2011.

FRIES, P. On the status of theme in English: arguments from discourse. Forum Linguisticum, Lake Bluff, v. 1., n. 6, p. 1-38. 1981.

GLEASON, H. Introduction to descriptive linguistics. New York: Holt, 1965.

GLEASON, H. Contrastive analysis in discourse structure. monograph series on languages and linguistics, Washington, n. 21, 1968.

GREGORY, M. Towards communication linguistics: a framework. In: BENSON, J.; GREAVES, W. (Ed.). Systemic Perspectives on Discourse vol. 1. Norwood: Ablex, 1985.

HAIMAN, J.; THOMPSON, S. Clause combining in grammar and discourse. Amsterdam: John Benjamins Publishing, 1988.

HALLIDAY, M. A. K. Categories of the theory of grammar. Word, v. 17, n. 3, p. 241-292, 1961.

HALLIDAY, M. A. K. Language structure and language function. In: LYONS, J. (Ed.). New horizons in linguistics. Harmondsworth: Penguin Books, 1970.

HALLIDAY , M. A. K. Some lexicogrammatical features of the "Zero Population Growth Text". In: MANN, W.; THOMPSON, S. Discourse description: diverse linguistic analyses of a fundraising text. Amsterdam: John Benjamins, 1992.

HALLIDAY, M. A. K. On Grammar and grammatics. In: HASAN, R.; CLORAN, C.; BUTT, D. (Eds.). Functional descriptions: theory in practice. Amsterdam: John Benjamins, 1996.

HALLIDAY, M. A. K.; HASAN, R. Cohesion in English. London \& New York: Longman, 1976. 
HALLIDAY, M. A. K.; MATTHIESSEN, C. Construing experience as meaning: a language based approach to cognition. London: Cassell, 1999.

HALLIDAY, M. A. K.; MATTHIESSEN, C. An introduction to functional grammar. 4. ed. London: Edward Arnold, 2014.

HALLIDAY, M. A. K.; McDONALD, E. Metafuncional profile of the grammar of chinese. In: CAFFAREL, A.; MARTIN, J.; MATTHIESSEN, C. (Ed.) Language typology: a functional perspective. Amsterdam: John Benjamins Publishing Company, 2004.

HASAN, R. On the notion of text. In: PETOFI, J. (Ed.). Text vs. sentence: basic questions of text linguistics. Hamburg: Helmut Buske, 1979.

ILARI, R. Perspectiva funcional da frase portuguesa. Campinas: Unicamp, 1992.

KOCH, I. Tematização e rematização. In: JUBRAN, C. C. A. S.; KOCH, I. G. V. (Org.). Gramática do português culto falado no Brasil. Campinas: Unicamp, 2006.

KOCH, I. Ler e escrever: estratégias de produção textual. São Paulo: Contexto, 2011.

KOCH, I.; ELIAS, V. Ler e compreender os sentidos do texto. São Paulo: Contexto. 2006.

KOCH, I.; MARCUSCHI, L. Processos de referenciação na produção discursiva. DELTA, São Paulo, vol. 14, número especial, 1998.

LEMKE, J. Semiotics and education. Toronto semiotic circle monographs: working papers and Prepublications, 1984.

LEMKE, J. Discourse and organizational dynamics: website communication and institutional change. Discourse and Society, v. 1, n. 10, p. 21-48, 1999.

MARCUSCHI, L. Linguística de texto: o que é e como se faz. Recife: Editora da UFPE, 1983.

MARTIN, J. English text: system and structure. Philadelphia: John Benjamins Publishing Company, 1992.

MARTIN, J. Systemic functional grammar: a next step into the theory - axial relations. Beijing: Higher Education Press, 2013.

MARTIN, J.; ROSE, D. Working with discourse: meaning beyond the clause. 2. ed. London: Continuum, 2007.

MATHESIUS, V. Functional linguistics. In: VACHEK, J.; DUŠKOVÁ, L. Praguiana: some basic and less known aspects of the prague linguistic school. Amsterdam: John Benjamins, 1983.

MATTHIESSEN, C. Interpreting the textual metafunction. In: DAVIES, M.; RAVELLI, L. (Ed.). Advances in systemic linguistics. London: Pinter, 1992.

MATTHIESSEN, C. Lexicogrammatical cartography: English systems. Tokyo: International Language Science Publishers, 1995. 
NEIS, I. Por uma gramática textual. Letras de Hoje, n. 44, p. 35-52, 1981.

O'DONNELL, M. The UAM CorpusTool: software for corpus annotation and exploration. In: BRETONES CALLEJAS, C. et al (Ed.). Applied linguistics now: understanding language and mind. Almería: Universidad de Almería, 2008.

PIKE, K. Linguistic Concepts: an introduction to tagmemics. Lincoln: University of Nebraska Press, 1982.

PONTES, E. O tópico no português do Brasil. Campinas: Pontes, 1987.

ROSE, D. A systemic functional approach to language evolution. Cambridge Archaeological Journal, v. 16, n. 1, p. 73-96, 2006.

SAUSSURE, F. Curso de linguística geral. São Paulo: Cultrix, 2006.

VILELA, M.; KOCH, I. Gramática da língua portuguesa: gramática da palavra, gramática da frase, gramática do texto/discurso. Coimbra: Almeidina, 2001.

ZAPPAVIGNA, M.; MARTIN, J. R. Discourse and diversionary justice: an analysis of youth justice conferencing. London: Palgrave Macmillan, 2018.

Recebido: 25/07/2018

Aceito: 11/02/2019

Publicado: 15/02/2019 